\title{
En torno a las brigadas culturales. Entrevista a Vidaluz Meneses
}

About Cultural Brigades. Interview with Vidaluz Meneses

Gema D. Palazón

UNIVERSITÉ DE LILLE III · gema.palazon@gmail.com

DOI: 10.7203/KAM.6.7847

ISSN: 2340-1869

VIDALUZ MENESES es autora de La lucha es el más alto de los cantos. Diario de campaña: Brigada Cultural 'Leonel Rugama', testimonio crucial sobre las brigadas culturales en Nicaragua.

Poeta, articulista, promotora cultural. Nació en Managua, en 1944. Licenciada en Humanidades con mención en Bibliotecología de la Universidad Centroamericana (UCA), Managua. Fue Decana de la Facultad de Artes y Letras de esa universidad.

Cofundadora de la Asociación Nic. de Escritoras (ANIDE)y su primera Presidenta; integró su Junta Directiva en distintos períodos siendo el último 2007-2009. También cofundadora y ex Coordinadora de la Red Nic. de Escritoras y Escritores (Renies). Es Propietaria por Nicaragua ante la Asociación Centroamericana de Escritoras/es (ADECA), miembro de la Junta Directiva del Pen Internacional, capítulo Nicaragua y actual Presidenta del Centro Nicaragüense de Escritores (CNE)en el 2012.

Además de los libros publicados detallados a continuación, también ha publicado "Guía temática y analítica de los escritos a máquina de Pablo Antonio Cuadra" (1974-1978) y es autora de varios ensayos y artículos en diarios y revistas. 
En torno a las brigadas culturales. Entrevista a Vidaluz Meneses

Su obra poética ha sido publicada en suplementos culturales y revistas literarias nacionales y de otros países. Ha sido traducida al inglés, alemán, italiano, francés, portugués y noruego y ha merecido numerosas distinciones por su obra y su amplio trabajo cultural.

KAMCHATKA. La lucha es el más alto de los cantos es un texto que se publica con un importante desfase temporal entre los hechos de los que da cuenta y su publicación. ¿Por qué no lo publicó en la década de los ochenta?

VidAluZ Meneses. Se supone que Rosario Murillo, Secretaria General de la Asociación Sandinista de Trabajadores de la Cultura lo debía de haber publicado pero posiblemente ya no hubo presupuesto para esto. El diario hubiese sido más rico pues yo le entregué a ella los cassettes con las entrevistas que menciono. Cuando yo decidí publicarlo ya no tenía acceso a Rosario, yo estaba en la oposición militando en el Movimiento Renovador Sandinista que llevaba como candidato a Herty Lewites quien después de haber ejercido como Alcalde de Managua por el FSLN, intentó ir de candidato a la Presidencia de la República, pero Daniel ya no aceptó eso porque eran sus propias aspiraciones. Herty, como otros líderes, fue expulsado del Frente. Rosario lo insultó en una carta pública.

KАMCHAтKA. Es decir, que inicialmente el material que dio lugar al diario eran una serie de entrevistas grabadas en los ochenta que finalmente no pudo recuperar para la redacción de La lucha... ¿Cómo fue la redacción o cómo afrontó esa dificultad para escribir tanto tiempo después su testimonio?

VIDALUZ MENESES. Así es. Yo no sé qué hizo Rosario con el material grabado que al menos yo le entregué, no sé si los escritores de otras brigadas lo hicieron. La verdad es que no intenté pedírselo porque seguramente no iba a tener voluntad de entregármelo por estar yo en la oposición.

KamChatKa. Según el prólogo, el texto se escribió en 2006, tan solo unos meses antes de las elecciones que volvieron a situar al FSLN en el poder, esta vez por la vía de las urnas. ¿Cuáles fueron los motivos que le llevaron a publicar el texto en ese momento?

VIDALUZ MENESES. Contribuir con la campaña del MRS haciendo un homenaje a esos héroes anónimos que contribuyeron y dieron su vida por el proyecto revolucionario.

KAMCHATKA. Entiendo que la publicación en esa época no fue, entonces, casual. ¿Cree que existen diferentes memorias ligadas al sandinismo? Me refiero sobre todo a las diferencias con la línea vinculada al 'orteguismo'. Lo que quiero decir es si La lucha... pretendía seguir reivindicando el ideal revolucionario más allá de las filas del FSLN (como partido político) 
VIDALUZ MENESES. Así es. Cardenal ha dicho que él no es político, que él es revolucionario. Yo me identifico con él en ese aspecto. Yo creo que la condición de revolucionaria es aquella por la que siempre estás dispuesta a cambiar lo que no es justo. En ese sentido también para mí es un valor cristiano, Jesús nos enseñó a no 'instalarnos'.

KAMCHATKA. El Ministerio de Cultura apostó fuerte por la creación popular a través de numerosos mecanismos que pretendían convertir al pueblo en productor cultural (y en esa línea se instauraron los talleres de poesía, los talleres de historia oral, etc). Sin embargo, al mismo tiempo, el Ministerio de Cultura reservó un espacio para los artistas profesionales, la ASTC (Asociación Sandinista de Trabajadores de la Cultura). ¿Fue esta una contradicción interna en la política cultural sandinista?

VIDALUZ MENESES. No debía haber sido contradictorio. El Ministerio era la institución del Estado que debía atender tanto a los artistas profesionales como al movimiento de aficionados. El Ministerio tenía escuelas, suscribía convenios con los distintos países, desarrollaba un amplio programa de capacitación y promoción.

La ASTC debía haber atendido los intereses gremiales de los artistas. A mi modo de ver, debían de haber sido complementarios.

KAMCHATKA. En la práctica, parece que no fue así y que de hecho las tensiones internas acabaron por establecer dos centros de poder -Rosario Murillo al frente de la ASTC por un lado y Cardenal por otro. Mi pregunta tenía que ver con si esas tensiones habían sido generales entre los artistas profesionales y los otros proyectos del ministerio de cultura.

VIDALuZ MENESES. Sí, de hecho se establecieron dos centros de poder en cultura. Si entiendo bien la pregunta, entre los artistas y escritores unos cuantos tuvieron mayor afinidad con Rosario, otros con Cardenal y a una gran mayoría creo que le era indiferente.

KAMCHATKA. ¿Cuál era exactamente la función de las brigadas culturales en el contexto revolucionario?

VIDALUZ MENESES. En primer lugar de animación y apoyo solidario, debíamos de contribuir a mantener en alto la moral de los combatientes.

En segundo lugar, aunque no lo hicieron explícito, era una manera de comprometernos participando de alguna manera en la defensa armada de la revolución. (No ser artistas de salón) Fue el mismo sentido de las brigadas que salieron a los cortes de algodón, caña y café. 
KAMCHATKA. A pesar de que su libro se inscribe en el género íntimo y privado del diario, La lucha es el más alto de los cantos, es en realidad un proyecto colectivo escrito en colaboración o al menos inspirado en las conversaciones con otros integrantes de la brigada. ¿Cómo fueron el proceso de elaboración del texto y esos encuentros?

VIDALUZ MENESES. Básicamente fueron los apuntes que tomé en una libreta a lo largo de toda la gira. 23 años después invité a algunos compañeros para recordar y agregar detalles que hubiese olvidado, pero no llegaron todos los que invité y no hubo mayores aportes pues el proceso era intenso y seguramente se les cruzaba en la mente con otras experiencias vividas. Lo nuevo fue la información que aportó Roberto Sánchez, desde su cargo de Relaciones Públicas del Ejército y es que nuestra brigada fue enviada a una zona fronteriza que era objetivo de la contrarrevolución para tomarse un territorio y declararlo liberado, tal como lo cuento en el prólogo: la llegada de la Junta de Gobierno como expresión de un gesto soberano era imprescindible y nuestra brigada sirvió de elemento distractor, en el mejor de los casos, contribuimos al 'diversionismo' y en el peor, fuimos señuelos para entretener la atención de la contra y que los máximos dirigentes se desplazaran con mayor seguridad hacia el objetivo.

KAMCHATKA. ¿Cómo circuló el texto en Nicaragua en términos de recepción? ¿Quién era para usted el destinatario principal de esos recuerdos?

VIDALUZ MENESES. La distribución de libros ha sido una limitante en nuestro país, hubiese querido que llegara a la juventud, pero no estoy segura que eso se logró.

KAMCHATKA. ¿Qué mensaje le gustaría transmitir a esos jóvenes?

VIDALUZ MENESES. Que aunque no ganamos hubo buena fe y muchísima generosidad sobre todo de miles de jóvenes que perdieron la vida. En las notas que escribió Carlos Meneses, escritor peruano, y que aparece en la contraportada del libro, él recoge lo que percibe del diario: la fraternidad, la dignidad en medio de la pobreza de recursos.... Yo considero que la dirigencia no estuvo a la altura de esa generosidad.

KAMCHATKA. Una constante que se hace presente a lo largo de todo el diario es la necesidad de consignar más que la experiencia personal, la reconstrucción de vidas perdidas en el proceso revolucionario. A menudo, aparecen los nombres y apellidos, las historias de personas anónimas que participaron en la lucha y que murieron en ella. ¿Fue consciente de ello en el proceso de redacción o fue esa una de las motivaciones para escribir el texto? 
En torno a las brigadas culturales. Entrevista a Vidaluz Meneses

VIDALUZ MENESES. Totalmente consciente. Nosotros/as corrimos riesgos, pero eran miles los jóvenes que fueron movilizados y que murieron. Ellos asumieron la peor parte. Lo mínimo que podía hacer era recoger un testimonio.

KAMCHATKA. Recientemente, se han venido publicando numerosos textos de carácter testimonial de la mano de muchos protagonistas con cargos más o menos relevantes durante la insurgencia o en el periodo revolucionario. ¿Qué cree que puede aportar el testimonio a la historia de Nicaragua hoy?

VIDALUZ MENESES. El proceso revolucionario fue tan complejo que esos testimonios contribuyen a reconstruir los hechos de la historia reciente de Nicaragua.

KAMCHATKA. A diferencia de otros testimonios que han aparecido recientemente en los que emergen con fuerza voces más individuales que se centran en la experiencia personal, La lucha... sigue apostando por una dimensión colectiva y, a pesar de que el prólogo y el epílogo constituyen un paratexto importante para establecer las coordenadas de lectura dentro del panorama político nicaragüense actual, el texto no pasa factura interna al FSLN, sino que rescata la pureza y la generosidad con que se participó en la lucha revolucionaria. ¿Cómo conciliar pasado y presente del sandinismo?

VIDALUZ MENESES. Es cierto que no paso factura a la dirigencia del FSLN, me interesó más la exposición de los hechos para que estos dirigentes lean y juzguen su propia actuación desde su conciencia. También es que en mi caso, yo no participé obligada, ni siquiera quise ser miembro del partido FSLN no tenía por qué culpar a quienes nos mandaron a los frentes de guerra.

Michele Najlis, que si fue una destacada militante de los inicios del FSLN, nos preguntaba a varias mujeres y se preguntaba a sí misma porqué toleramos tanto. La única razón que ha existido es que estábamos en guerra y no podíamos correr el riesgo de dividirnos, a lo que yo podría agregar: deseábamos que el proyecto se realizara contra viento y marea y por eso no medíamos los costos.

KАMCHATKA. La lucha es el más alto de los cantos dedica parte de su prólogo a la muerte de Herty Lewites y se publica en el contexto electoral en el que el MRS concurría como una fuerza política sandinista alternativa al FSLN. ¿Existen en Nicaragua diferentes memorias del sandinismo?

VIDALUZ MENESES. Si, yo creo que hay varias memorias. Una desde las filas del Frente, son los cuatro tomos de Memorias de la lucha sandinista publicados por la Comandante Guerrillera Mónica Baltodano que a través de entrevistas realizadas en un programa de radio y directamente con combatientes, intelectuales y personas de la sociedad civil, da una visión amplia sobre la forma en que nos integramos distintos sectores de la población a la revolución. Las memorias de escritores como Adiós 
En torno a las brigadas culturales. Entrevista a Vidaluz Meneses

muchachos de Sergio Ramírez; El país bajo mi piel, de Gioconda Belli; La revolución perdida, de Ernesto Cardenal; Lanza en ristre: razones para vivir y morir de Heberto Incer; Perra vida, de Juan Sobalvarro, entre las que recuerdo en este momento.

KAMCHATKA. ¿En qué tradición (si es que hay alguna), se inscribe La lucha es el más alto de los cantos?

VIDALUZ MENESES. En el Testimonio. No había sido una tradición en la literatura nicaragüense, es con la revolución que surge profusamente.

KAмCHATKA. En los 90, algunos críticos (como Jorge Eduardo Arellano o Isolda Rodríguez) celebraron la vuelta de la ficción a la literatura nicaragüense y proclamaron el fin del testimonio una vez fracasada la revolución. Su testimonio apareció en 2006 y muchos otros lo han seguido haciendo desde la década de los noventa hasta el presente. La práctica testimonial parece obstinada en desmentir a la academia, ¿por qué escogió esa particular tradición para La lucha...?

VIDALUZ MENESES. Creo que es una posición ideológica la que expresan Jorge Eduardo e Isolda. No la comparto.

KAMCHATKA. El libro está dedicado a los muertos en el proceso revolucionario y "a quienes sobreviven y me los encuentro en las nuevas batallas ciudadanas tratando de preservar los ideales que nos unieron sin distingos políticos”, ¿cuáles son las nuevas batallas que enfrenta la sociedad nicaragüense hoy?

ViDAluZ Meneses. Lo que queríamos la mayoría cuando triunfó la revolución: Democracia, justicia social, equidad de hombres y mujeres, derechos de las distintas etnias. Se han sumado otras: defensa del medioambiente, de la diversidad sexual.

KAMCHATKA. ¿Ha releído La lucha... después de su publicación? Si es así, ¿qué sentimientos le produce?

VIDALUZ MENESES. Me veo muy radical políticamente pero era la única manera de acompañar ese proceso en el que la juventud llevó la peor parte.

KAMCHATKA. El último día que aparece en el diario concluye no con la vuelta de la brigada cultural a Managua, sino con la noticia inquietante de una invasión conducida por la Contra desde Honduras, tan sólo unos días después de que la brigada haya estado recorriendo territorios fronterizos. Las últimas frases, sin embargo, están cargadas de esperanza: “No dudamos que “¡No pasarán!”, más que nunca nos 
convencemos de la capacidad, de la disponibilidad combativa, de nuestras armas, de nuestra disciplina, de nuestra indeclinable decisión de vencer...”. ¿Por qué eligió ese final para el diario a pesar del desenlace que finalmente tendría la revolución?

VIDALUZ MENESES. Porque esos eran los sentimientos que teníamos al concluir la misión, nosotros nos veníamos y los combatientes se quedaban, era el mensaje necesario que debíamos de dejarles, de autoafirmación.

KAMCHATKA. ¿Cómo cree que puede leerse ese final por las nuevas generaciones de Nicaragua, aquellas que no vivieron el proceso revolucionario?

VIDALUZ MENESES. Posiblemente que ha sido una historia de perdedores. Yo acabo de concluir mis memorias, desde mis ancestros hasta los años noventa que posiblemente salgan publicadas este próximo año 2016 pues si bien la editora la tiene en sus manos desde hace meses, no se puede publicar el libro en ausencia de la autora. Mi mamá leyó el manuscrito y la noté molesta, pensé que era por la opción que yo tomé y de la que no me arrepiento a pesar de todo. Pero no, creo que le molestó que tanta entrega, no sólo mía, sino de tantas personas, aparentemente no sirvió para nada.

KaMCHATKA. ¿Y usted qué opina? ¿Sirvió?

VIDALuZ Meneses. Bueno, mi último libro de poesía se llama Todo es igual y distinto, en mis memorias cuento eso, que en los años noventa regresé a trabajar en la Universidad Centroamericana y de pronto me vi haciendo lo mismo que hacía antes de la revolución: pedir apoyo a los ricos para los estudiantes pobres. Sentí como que no habíamos hecho nada después de tanto sacrificio, pero realmente luego concluí que habían situaciones parecidas al pasado pero también era distinto. La pobreza en las que nos dejó la guerra nos hacía enfrentarnos a iguales problemas pero estábamos desafiados a dar respuestas distintas. 